\title{
Net Zero Is Not A Choice But An Ethical Practice - Evolution Of Net Zero Building
}

\author{
MING HU \\ University of Maryland
}

Buildings are responsible for approximately one-third of worldwide carbon emissions and account for over 40 percent of primary energy consumption globally. High-performance building design has become an overarching goal for the building and construction industry. The important and trendy domains in the built environment are the "resilience" and "net zero" associated with high-performance design that have their origin in ecology. The performance of building and energy efficiency is one of the common measuring indexes accepted by multiple fields. The ultimate goal of a net zero building has become a hot trend, and an off-grid building has become the ultimate "high-performance" standard. The fundamental misleading concept around contemporary net zero buildings is that a net zero building is one type of building, one type of design process. Instead, if we trace the origin of net zero energy back to its ecological root, we should consider net zero building as a guiding design principle for all buildings and a professional ethic for all practitioners. Just as all mechanical design has to follow the laws of thermodynamics, all building design should keep the net zero concept as the core consideration, not an add-on item. This paper first outlines and explains the ecology origin of the net zero concept and then provides a comprehensive overview of the net zero movement from the 1930 s to present time. Five critical development periods are identified, and major events, developments, and influential thinkers are described and explained. Based on the comprehensive review, two major divergences of the net zero movement in the building industry from its ecological origin are noted.

\subsection{ORIGIN OF THE CONCEPT OF "NET ENERGY"}

The concept of "net energy" has its origin in and close relationship to ecology. In 1920, Frederick Soddy, an English chemist and Nobel prize winner, first offered a new perspective on economics rooted in physics: the law of thermodynamics. Soddy brought up the importance of energy for social progress based on real wealth formation, as distinct from virtual wealth and a debt accumulation process [1]. He suggested that a detailed accounting for energy use could be a good alternative to the monetary system since the conventional monetary system treated economics as a perpetual motion machine. But in reality, as with any commodity, the actual wealth flow should obey the laws of thermodynamics [2]. However, his theory was largely criticized and ignored in his time since he came to orthodox economics as a critic instead of a student. The ignorance and criticism of Soddy's theory contributed to the long-term lack of associated research development between 1930 to 1970 .
There is large gap between 1930 to 1970 . The only mentionable development is the "Technical Alliance." A group of architects, engineers, economists, and ecologists formed a professional group named the "Technical Alliance" in 1919 and disbanded in 1921. It started an Energy Survey of North America with an aim to document the wastefulness of the entire society, which is the first attempt to quantify "net energy" [2].

In the 1970s, Romanian-American mathematician and economist Nicholas Georgescu-Roegen further developed ecological economics or eco-economics based on Soddy's concepts. This is a transdisciplinary and interdisciplinary field of research that includes ecology, economics, and physics. Georgescu-Roegen proposed the application of entropy law in the field of economics, where he argued that all natural-resource consumption essentially is irreversibly, which had a profound impact on net energy flow or life-cycle thinking of natural resources. He was the first economist of some standing to put forward theories on the premise that all earth's mineral resources will eventually be exhausted at some point [3], and the concept of depletion of natural resources eventually led to the movement of sustainable development. As he stated, "An unorthodox economist-such as myself-would say that what goes into the economic process represents valuable natural resources, and what is thrown out of it is valueless waste" [4].

Another important development in the 1970s was the publication of the article "Energy, Ecology, \& Economics" and the book Environment, Power, and Society by ecologist Howard Odum, who tackled economic issues using ecological theories based on energy fundamentals. His energy economics were based on the comprehension that energy is the foundation for all forms of life and transformable. He stated that "the true value of energy to society is the net energy, which is that after the costs of getting and concentrating that energy are subtracted" [5]. His view of studying ecology as a large and integrative ecosystem paved the way to understanding how the different aspects of a whole ecosystem influence each other. In the latter part of his career, he developed a concept of energy in the 1990s. He said that "energy is a measure of energy used in the past and thus is different from a measure of energy now. Energy has attracted attention from academic researchers and is being applied to research in building and construction industry besides natural ecosystem" [6 7]. 


\subsection{THE EVOLUTION OF NET ZERO IN THE BUILT ENVIRONMENT}

\subsection{0 - 1969 Early Solar House}

Some of the first documented attempts toward zero energy building emerged as an effort to achieve net zero heating and cooling in solar houses, which originated around the 1930s. Several of the earliest pioneer buildings include the 1939 MIT Solar House I, which introduced a large solar thermal collector and water storage [24], and the solar air collector and rock mass storage used in Bliss House, which has become one of most applied solar technologies still being used today. In September 1936, the Dean of the School of Engineering, Vannevar Bush, the renowned American inventor, engineer, and the early administrator of the Manhattan Project, took an interest in solar energy, and his idea of flat sun collectors impressed Boston-based philanthropist Godfrey L. Cabot. Mr. Cabot donated nearly $\$ 650,000$ to MIT in 1938 and particularly instructed that the fund should be used "in development of the art of converting the energy of the sun to the use of man by mechanical, electrical, or chemical means." The fund stimulated the formation of MIT's Solar Energy Fund. During the 50 years the Solar Energy Project lasted (1938-1988), a series of six experimental prototype solar houses were built [8].

\subsection{0-1989 First Energy Crisis and Emergence of the Net Zero Energy Building}

The first wave of the energy crisis in the 1970s sparked the energy-efficiency improvement movement. On October 17, 1973, six Arab and non-Arab members of the Organization of the Petroleum Exporting Countries decided to raise the price of oil exports by seventy percent. On the same day, nine Arab oil-producing countries imposed an embargo on oil supplies to the United States and the Netherlands in response to the outbreak of the war [8]. The consequences from the two dramatic actions were hard-felt in United States and the Netherlands but the impact also spread worldwide. At that time, scientists and engineers from various fields, including physicists and chemists, started to pay more attention to the energy consumption pattern in United States. Among them was the "godfather of energy efficiency" Arthur Rosefeld [wiki]. He noticed that the United States consumed about twice the energy per capita compared to European counterparts, yet both had a comparable standard of living [10]. This proved two facts: first, energy could be conserved through user behavior such as turning off lights in unoccupied rooms, and second, higher energy consumption did not translate to faster economic development or a higher living standard. He asserted that if Americans had used energy at the same rate as Europeans or Japanese, the United States could be exporting oil in 1973. Later, he met up with colleagues from the Princeton Center for Energy and Environmental Studies, Professor Robert Socolow and Professor Sam Berman from Stanford university in 1974, and agreed on the need to conduct a study on energy efficiency and conservation. With the financial support from the National Science Foundation and the Federal Energy Agency (which became the Department of Energy), the group held the first meeting at Princeton and invited experts in building, industry, transportation, and utilities. During the meeting, they discussed the cause of energy behavior in United States as being cheap energy and abundant resources. The results of the meeting were compiled and published as the famous Princeton Study.

The influence of the first energy crisis in the building industry is profound. The energy crisis ignited an energy upheaval that reshaped the entire world, touched everyone's daily life, and forced a paradigm shift in the building and construction industry that is still not complete. Since 1973, a wide range of building energy-efficiency methods have evolved: from the solar house, which focused on harvesting natural renewable energy from the sun, to a more holistic energy demand reduction effort. Between 1970 and 1990, the concept of net zero energy officially emerged as a viable design concept with the energy-saving method. Multiple organizations and programs were established with the goals of producing an energy-efficient design and decreasing energy consumption. Most importantly, one of the very first net zero building experiments took place: the Danish zero-energy house done under the guidance of Professor Vagn Korsgaard from the Technical University of Demark. This project took place during the period 1976 to 1977 and was situated at the outskirts of Copenhagen. The building was equipped with highly insulated construction materials, a $42 \mathrm{~m} 2$ flat-plate solar collector, and a seasonal water storage tank with a capacity of $30 \mathrm{~m} 3$ [12]. This project won the Passive House Pioneer Award in 2013, and Passive House founder Dr. Wolfgang Feist made this remark: "The construction of this building was thus an important basis for later developments in Europe and around the world" [13]. This project might also have been the first energy-efficient building experiment to use the term of "net zero."

\subsection{0-2006 Second Energy Crisis}

The second wave of the energy crises was closely related to the First Gulf War. On August 2, 1990, Iraq invaded Kuwait. The war lasted for nine months and resulted in a significant increase in oil and natural gas prices. Even though the price spike was less extreme and lasted for a shorter time than the previous energy crisis, collective efforts in certain academic and federal agencies around the world produced some promising efforts, proving the concept of net zero energy and completing some exemplary projects. When Clinton and Gore took office in 1992, the political environment for energyefficiency research and projects had become friendlier. In 1996, the United States, Canada, and Mexico got together and produced the North American Energy Measurement and Verification Protocol, which was the first official attempt to provide consistent procedures that could be implemented by 
different stakeholders on energy projects to quantify energy conservation measure performance and energy savings. This protocol has been largely driven by industry and reflects a broad industry consensus. This document has become an important reference in the building energy-efficiency program in North America. It also has been translated into other languages. During this period, the consensus around the definition of net zero energy started to emerge. At the end of this period, in 2006, a National Renewable Energy Laboratory report pointed out the lack of a common definition of "zero energy" and stated that "a zero energy building can be defined in several ways, depending on the boundary and the metric." The terms net zero site energy (NESE), net zero source energy (NZSE), net zero energy cost (NZEC), and net zero energy emissions (NZEE) were proposed [18] and became the common set of definitions used in the United States.

\subsubsection{7-2010 Financial Crisis and Rapid Development of Net Zero Energy Building}

The last recession, which officially lasted from 2007 to 2009, started with the bursting of the house bubble. The Great Recession started in United States and then went beyond the boundary of the United States. The crisis spread to Europe rapidly and affected the 28 member states of the European Union and many other European and Asian counties, including Finland, Israel, Japan, Norway, and Singapore, during the years between 2006 to 2013. A large number of South American countries also suffered huge impacts. The building and construction industry was one of the hardest-hit sectors. In the United States, construction spending reached a historical high at the end of 2006 of $\$ 1,177.7$ billion and then decreased until 2011 even though the recession officially ended in 2009. The recovery of the building industry has been very slow. It was not until the end of 2016 that construction spending returned to the same level as before the recession at $\$ 1,181.5$ billion, which did not take inflation into consideration. However, there was a small segment of the building industry that boomed during the economic downtown: the green building industry. LEED project registrations continued to increase throughout 2008 and into 2009. During 2008 , there were 2,100 projects registered on average each quarter. There were 2,300 projects registered during the first quarter of 2009. Between 2010 and 2011, LEED building registration increased $9 \%$ increase [14] despite all other sectors in building industry continuing to decline. The fast development of green buildings and sustainable buildings shared the common ultimate goal of achieving net zero energy, which is actually the mirror image of the events/developments that occurred during the first oil crisis. The oil crisis and the economic crisis all pumped people to find ways to use resources and energy in a more efficient way in order to produce more with limited inputs.
During this period, the combination of new knowledge development from the scientific community, the advancement in building technologies, natural disasters, and favorable business and political leadership created a sense of urgency to mitigate the environmental impact of the built environment and delay the risk of climate change. A variety of federal agency and industry regulators proposed to define guidelines to measure and quantify net zero energy building across the globe. In 2008, the National Science and Technology Council (NSTC) issued the Federal Research and Development Agenda for Net-Zero Energy, High-Performance Green Buildings (NSTC 2008). The National Institute of Standards and Technology defined net zero energy buildings as those that produce as much energy as they consume over a defined period and proposed measurement techniques [15]. Those guidelines set an agreeable platform and consistent technical guidelines worldwide so that practitioners, researchers, and regulators could communicate in a common language. The European parliament defined the "nearly zero energy building" as "a building that has a very high energy performance as determined in accordance with Annex I. The nearly zero or very low amount of energy required should be covered to a very significant extend by energy from renewable sources, including energy from renewable sources produced on-site or nearby" [16].

\subsection{1-2017 Financial Recovery and Beyond Net Zero} Energy Building

As near zero energy and net zero energy building became the new goal and standard globally, the role of building materials and embodied energy or related $\mathrm{CO} 2$ emissions became more and more important [17]. Focusing only on energy efficiency entails a clear risk of having an energy-efficient building that does not perform well regarding other environmental criteria. Also, the environmental impact of the whole building service life becomes a concern to developing and developed countries. The building sector generates about "one third of all waste and is associated with environmental pressures that arise at different stages of a building's life-cycle including the manufacturing of construction products, building construction, use, renovation and the management of building waste...." [European Commission 2014]. During the financial recovery, since the economic and energy conservation pressures have been relaxed, we have seen expansion of the net zero concept. The net zero energy building has been extended to Zero Energy Campus(ZEC) based on a source energy, Zero Energy Portfolio(ZEP) based on a source energy, Zero Energy Community(ZEC) based on a source energy [18].

\subsection{DIVERGENCE AND DEVIATION}

\subsection{Self-Sustaining and Self-Organizing}

From the 1970s concept of net energy flow to the current defined net zero energy building, how far we have moved 
away from its ecological origin? The core principles of energy flow in the ecosystem is its self-organization and hierarchy. Odum outlined the two principles in his 1971 book Environment, Power and Society.

Energy hierarchy is the fifth energy law that Odum proposed as a system effect of the second energy law: a hierarchy is "a design in which many units of one kind are required to support a few of another." Self-organization is "the downstream products have less energy to feed back and amplify" [23]. Together, self-organization and hierarchy create a centralized hierarchical pattern in nature. Odum described the common systematic development and growth pattern found in the ecosystem as "systems converge the transformation products to centers spatially, they concentrate these flows so that the feedback out from the centers is concentrated enough to have a strong effect by spreading its useful work over the contributing area" [23]. Nature is the best author documenting such hierarchy. We can find the pattern of a small center aggregating towards a larger center in tree trunks, leaves, pinecone seeds, rivers, and even air bubbles. When we exam the maps of historical towns and cities across different cultures, regardless of the geographic location or environmental conditions, small neighborhood centers converge their outputs to larger district centers that represent the large scale. These district centers then converge to even bigger city centers at the next level. Larger historical metropolitan cities might have multiple city centers, and every one of those centers has its associated convergence pattern (figure 1). The hierarchy of neighborhoods, districts, and city centers could be seen in historical Beijing, Saint Petersburg, and Pittsburgh. It represents not only a principle of geography but also the connection between spatial organization and energy hierarchies. And this connection has influenced many town plans and urban designs. Through such a selforganizing mechanism, the resources and materials being optimized and used through circulation between small and large centers produces optimized efficiency as a comprehensive system. When the different parts of a city or a town are brought together, the interaction between different parts plays equally important roles at the same level in how the individual parts would function. The overall organization of the whole system is equally important for the system's final performance, if not more so than the individual part's function. In this way, historic cities and towns function as an integrated living system, and energy and materials could be distributed and circulated on as-needed basis.

This ecological principle and systematic thinking has undergone some twists from 2000 in the building industry when most efforts around net zero building focused on searching for a consistent framework to define what is net zero. Attention has been undividedly given to technologies, advanced building materials, and end-energy usage. The isolated attention and heavy dependency on individual products or advanced building systems indeed was a form of defying net zero's ecological origin and principles.

\subsection{The Missing Embodied Energy}

Most net zero building focuses on new construction instead of existing building renovation. This might be due to the fact that the public has the perception that retrofitting existing building is a difficult and unpopular thing to do. Another cause for this narrowed focus is the lack of awareness and knowledge of embodied energy. Embodied energy is defined as the total energy inputs consumed throughout a product's life-cycle. Initial embodied energy represents energy used for the extraction of raw materials, transportation to factory, processing and manufacturing, transportation to site, and construction. Once the material is installed, recurring embodied energy represents the energy used to maintain, replace, and recycle materials and components of a building throughout its life. Energy is embodied in everything we use every day: from food to clothing to cars, as well as buildings and all the materials used in them. The architecture and engineering professions continue to drive down the energy buildings consume in their operations through initiatives like the AIA 2030 Commitment. As buildings consume less energy in operations, the energy embodied in the buildings' materials will become increasingly important as a percentage of a building's total energy footprint. Academic studies have illustrated that embodied energy accounts for the majority of a building's energy footprint for approximately the first 15 to 20 years of a building's life-cycle. The amount of embodied energy in a building depends on the material resources. Where did we get our construction materials? How far did we need to transport the raw materials to manufacture for processing? How did we extract the raw materials? Do we have enough material in this region to support construction activities in the next decade? These are all necessary questions and such studies have been largely ignored in the current adopted net zero energy building calculation. Today, no country has requirements regarding embodied energy requirements for buildings [29]. Some sustainable building rating systems include some requirements for taking the environmental impact of building materials into consideration, such as LEED and the living building challenge. However, only two of twelve net zero energy building definitions in the Marszal et al. [20] study include embodied energy in the primary energy balance. The concept of incorporating embodied impacts in the net zero building design process is particularly important because the typical net zero energy and net zero emission concept used in North America, Europe, and Asia focuses only on the energy used during the operation stage. This omits the implications that arise over the full life cycle [21].

\subsection{CONCLUSION}

Maintaining the balance of energy flow and material flow is the natural law in an ecosystem. The concept of energy 
balance in a building originated from the ecology field. After several decades of development, energy-efficient practices and sustainable building designs have become a choice, a sectarian one. When a different political party took over the US administration, the policy, the funding, and the ideology shifted, as explained in Section 2. Environmental and energy-conscious living has become a trait dividing people into different social groups. Net zero building has been the choice of certain groups. But in nature, in the larger ecosystem in which we live, the law of energy flow and hierarchy has never changed. What we are missing now is a standard practice integrating all necessary knowledge and methods for achieving net zero energy living. According to the American Institute of Architects (AIA) code of ethics and professional conduct, it requires the architect, during the schematic design phase and as part of its basic services, to discuss with the owners the feasibility of incorporating environmentally responsible design approaches into the projects [22]. Discussion is far from enough, though. Without enforcement, practitioners rarely proactively push forward a practical, energy-efficient design approach if there is no interest from owners or incentives from legislation. The lack of disciplined requirements is only one reason for today's selective energy-efficient building design practice. Another important reason is the lack of resource and means. The current approach to achieve net zero energy heavily depends on advanced technology and highly controlled building systems, which creates huge financial and technological barriers for many less resourceful projects and building owners.

Understanding the environment and society as a system means thinking about parts, processes, and connections [23] and should be the principle for all types of building design. The fundamentally misleading concept around contemporary net zero building is that net zero building is one type of building, one type of design process. Instead, if we trace the origin of net zero energy back to its ecological root, we should consider net zero building as a guiding design principle for all buildings and a professional ethic for all practitioners. Just as all mechanical design has to follow the laws of thermodynamics, all building designs should keep the net zero concept as the core consideration and not an add-on item.

\section{ENDNOTES}

1 Spash, Clive L., ed. Routledge Handbook of Ecological Economics: Nature and Society. Taylor \& Francis, 2017.

2 Hernandez, Patxi, and Paul Kenny. "From net energy to zero energy buildings: Defining life cycle zero energy buildings (LC-ZEB)." Energy and Buildings 42, no. 6 (2010): 815-821

3 Boulding, Kenneth Ewart. Ecodynamics: A New Theory of Societal Evolution. London: Sage, 1981

4 Georgescu-Roegen, Nicholas. "The entropy law and the economic problem." Valuing the earth: Economics, Ecology, Ethics (1971): 75-88.

5 Odum, Howard T. “Energy, ecology, and economics." Ambio (1973): 220-227.

6 Pulselli, R. M., Eugenio Simoncini, F. M. Pulselli, and S. Bastianoni. "Emergy analysis of building manufacturing, maintenance and use: Em-building indices to evaluate housing sustainability." Energy and Buildings 39, no. 5 (2007): $620-628$
7 Pulselli, Riccardo Maria, Eugenio Simoncini, and Nadia Marchettini. "Energy and Emergy-based Cost-benefit Evaluation of Building Envelopes Relative to Geographical Location and Climate." Building and Environment 44, no. 5 (2009): 920-928.

8 http://libguides. mit.edu/c.php?g=175920\&p=1160317

9 http://www.nytimes.com/1983/09/25/us/10-years-after-oil-crisis-lessonsstill-uncertain.html?pagewanted=all

10 Rosenfeld, Arthur H. "The art of energy efficiency: Protecting the environment with better technology." Annual Review of Energy and the Environment 24, no. 1 (1999): 33-82.

11 http://www.presidency.ucsb.edu/ws/?pid=32658

12 Esbensen, Torben Vesti, Torben V. Esbensen, and Vagn Korsgaard. Performance of the zero energy house in Denmark. Thermal Insulation Laboratory, Technical University of Denmark, 1977.

13 https://passivehouseplus.ie/blogs/ pioneer-award-for-1970s-zero-energy-house-in-denmark

14 https://www.usgbc.org/articles/leed-numbers-16-years-steady-growth

15 Korkmaz, Sinem, David Riley, and Michael Horman. "Piloting evaluation metrics for sustainable high-performance building project delivery." Journal of Construction Engineering and Management 136, no. 8 (2010): 877-885.

16 http://eur-lex.europa.eu/legal-content/EN/TXT/?uri=CELEX\%3A32010L0031

17 Alsema, E.A., Anink, D., Meijer, A., Straub, A. and Donze, G., 2016. Integration of Energy and Material Performance of Buildings: I= E+ M. Energy Procedia, 96, pp.517-528.

18 Torcellini, Paul, Shanti Pless, Michael Deru, and Drury Crawley. "Zero energy buildings: a critical look at the definition." National Renewable Energy Laboratory and Department of Energy, US (2006).

19 Berggren, Björn, Monika Hall, and Maria Wall. "LCE analysis of buildingsTaking the step towards Net Zero Energy Buildings." Energy and Buildings 62 (2013): 381-391.

20 Marszal, Anna Joanna, Per Heiselberg, Julien S. Bourrelle, Eike Musall, Karsten Voss, Igor Sartori, and Assunta Napolitano. "Zero Energy Building-A review of definitions and calculation methodologies." Energy and Buildings 43, no. 4 (2011): 971-979.

21 Lützkendorf, Thomas, Greg Foliente, Maria Balouktsi, and Aoife Houlihan Wiberg. "Net-zero buildings: incorporating embodied impacts." Building Research \& Information 43, no. 1 (2015): 62-81.

22 http://aiad8.prod.acquia-sites.com/sites/default/files/2017-02/B1012007\%20Commentary.pdf

23 Odum, Howard T., and Mark T. Brown. Environment, Power and Society for the Twenty-first Century: The Hierarchy of Energy. Columbia University Press, 2007.

24 Barber, Daniel. "LIVING WITH THE SUN: ARCHITECTURE AND THE ASSOCIATION FOR APPLIED SOLAR ENERGY, 1954-1958." In 2007. 2007. 